\title{
Tonsillectomy 30 years after Paradise: implosion of arguments
}

\author{
Jochen P. Windfuhr ${ }^{1} \cdot$ Jochen A. Werner ${ }^{2}$
}

Received: 12 January 2016/Accepted: 13 January 2016/Published online: 2 February 2016

(C) Springer-Verlag Berlin Heidelberg 2016

Sore throat remains a common disease to be managed by family physicians, pediatricians or otolaryngologists. Patients of all ages present with pain and odynophagia, with fever typically occurring in the pediatric population. It is imperative to decide whether the tonsils are involved or not, since viral inflammation of the entire oropharyngeal mucosa will not respond to antibiotic therapy. Therefore, clinically relevant and validated scores are suggested to decide whether prescription of antibiotic therapy is justified or not $[1,2]$. Astonishingly, these considerations are commonly not transferred to tonsillectomy, frequently acknowledged as a simple and minor procedure that will readily eradicate the source of infection in the throat. This misinterpretation of tonsillectomy ignores a guaranteed number of painful days after surgery and the risk of a potentially life-threatening bleeding complication [3]. What is the scientific point of view?

By the 1970s, the few existing randomized trials were seriously biased by many factors and the scientific evidence of the procedure was at best questionable [4, 5]. In March 1984, the New England Journal published the results of a complex clinical trial of Paradise and colleagues who evaluated the efficacy of tonsillectomy in children with sore throat [6]. The authors concluded that in severely affected children ( $\geq 7$ throat infections in the past year or $\geq 5$ in each of the past 2 years or $\geq 3$ in each of the past 3 years) the incidence of throat infections during the first 2 years after tonsillectomy was significantly lower and in the third year

Jochen P. Windfuhr

jochen.windfuhr@mariahilf.de

1 Department of Otorhinolaryngology, Plastic Head and Neck Surgery, Kliniken Maria Hilf, Sandradstr. 43, 41061 Mönchengladbach, Germany

2 University Hospital of Essen, Essen, Germany consistently favored the surgical groups compared to the non-surgical group. The benefit from surgery for children with less severe throat infections was insignificant due to spontaneous resolution of throat infections.

During the past decades, this unique paper served as an adequate answer to the allegation of tonsillectomy as "ritualistic surgery" [7]. Until this time, the teeth and tonsils in particular were acknowledged as major sources of primary infections that spread secondary to other body organs. Therefore, a wide array of unproven indications had existed to justify tonsillectomy, including rheumatic fever, endocarditis, myocarditis, pericarditis, nephritis, pancreatitis, chorea, peptic ulcer, appendicitis, and arthritis. Particularly the focal theory of infection considered tonsils as portals of infection and served for many years as a promoter of a technically trivialized tonsillectomy [8].

In the light of hundreds of thousands of procedures performed annually worldwide it is noteworthy to emphasize, that only seven studies dealing with the efficacy of tonsillectomy on the incidence of sore throat were found eligible for analysis in the latest and updated meta-analysis of the Cochrane Collaboration [4]. The evidence in two studies with adult patients was considered to be of low quality and their conclusion limited to 5-6 months after surgery. In five studies with children adequate information was considered to be available only for the first year following surgery which contrasts to the original statement of the authors. Children after tonsillectomy had three episodes of sore throat on average compared to 3.6 episodes experienced by children of the control group.

A closer look to the few obtainable national guidelines concerning indications for tonsillectomy reveals that the selection criteria of a 30-year-old study are still in practice conceding slight modifications. In other words, the 
indication of a painful and potentially life-threatening surgical procedure with a concealed and never conclusive mortality rate is based upon what the Cochrane Collaboration calls low to moderate quality evidence.

Because of the tendency of sore throat to improve with time, an observation period of at least $6[5,9,10]$ to 12 months [11] is currently suggested prior to consideration of tonsillectomy. Although this approach will help us to better estimate the spontaneous healing rate, a more scientific rationale is desirable. Adequate selection criteria have to be validated to assess the efficacy of tonsillectomy in the longterm on the prevention of further throat infections and/or their severity. Moreover, the impact of tonsillectomy on health-related quality of life has to be measured with adequate tools at the same time, particularly in children [4]. This is what we need so urgently.

\section{Compliance with ethical standards}

Conflict of interest The authors declare that they have no conflict of interest.

\section{References}

1. Fine AM, Nizet V, Mandl KD (2012) Large-scale validation of the Centor and McIsaac scores to predict group A streptococcal pharyngitis. Arch Intern Med 172:847-852
2. Windfuhr J, Toepfner N, Steffen G, Waldfahrer F, Berner R (2016) Clinical practice guideline: tonsillitis I. Diagnostics and nonsurgical management. Eur Arch Otorhinolaryngol [ahead of print]

3. Windfuhr JP, Schloendorff G, Baburi D, Kremer B (2008) Serious post-tonsillectomy hemorrhage with and without lethal outcome in children and adolescents. Int J Pediatr Otorhinolaryngol 72:1029-1040

4. Burton MJ, Glasziou PP, Chong LY, Venekamp RP (2014) Tonsillectomy or adenotonsillectomy versus non-surgical treatment for chronic/recurrent acute tonsillitis. Cochrane Database Syst Rev 11:CD001802

5. Windfuhr J, Toepfner N, Steffen N, Waldfahrer F, Berner R (2016) Clinical practice guideline: tonsillitis II. Surgical management. Eur Arch Otorhinolaryngol [ahead of print]

6. Paradise JL, Bluestone CD, Bachman RZ et al (1984) Efficacy of tonsillectomy for recurrent throat infection in severely affected children. Results of parallel randomized and nonrandomized clinical trials. N Engl J Med 310:674-683

7. Bolande RP (1969) Ritualistic surgery-circumcision and tonsillectomy. N Engl J Med 280:591-596

8. Grob GN (2007) The rise and decline of tonsillectomy in twentieth-century america. J Hist Med Allied Sci 62:383-421

9. http://www.sign.ac.uk/pdf/sign117.pdf

10. http://www.snlg-iss.it/en_lgn_tonsillectomy_2008

11. Baugh RF, Archer SM, Mitchell RB et al (2011) Clinical practice guideline: tonsillectomy in children. Otolaryngol Head Neck Surg 144:S1-S30 